\title{
Introducción a Estratos del tiempo ${ }^{1}$
}

\section{Reinhart Koselleck}

\begin{abstract}
A 1 hablar sobre el tiempo debemos apoyarnos en metáforas; porque al igual que el movimiento el tiempo solo es comprensible en unidades espaciales. El camino que se recorre de aquí hacia allá, el avance o el progreso mismo contienen imágenes a partir de las cuales se obtiene una intuición del tiempo. Para el historiador (Historiker), cuya actividad se vincula esencialmente a las historias (Geschichten), se hace inevitable recurrir a esas metáforas surgidas de la representación espacial. Ya que la historia (Geschichte) siempre tiene que ver con el tiempo, con tiempos (Zeiten) que, no solo metafóricamente sino también de modo empírico, quedan asociados a directrices espaciales, tal como lo indica el mismo "suceder" (geschehen): el verbo que antecede al vocablo Geschichte se refiere en principio a "apurarse", "correr" o "volar", o sea, al movimiento espacial. Todo espacio histórico se constituye en virtud de la fuerza del tiempo (Kraft derZeit); a través de la cual el espacio puede ser atravesado, volviéndose controlable política o económicamente. Aunque la fuerza metafórica de todas las imágenes temporales surja primariamente de las intuiciones espaciales, las indagaciones temporales y espaciales siempre se hallan entrelazadas.

Podría descartarse, como un simple juego de palabras, el hecho de que también la "historia" (Geschichte) admita una connotación espacial, al contener en sí misma "estratos" (Schichten). Pero la metáfora espacializadora que pluraliza el concepto de tiempo supone ya de por sí una ventaja: a la manera de su modelo geológico, los "estratos de tiempo" ("Zeitschichten") remiten a planos temporales (Zeitebenen) de distinta duración y origen que existen y actúan simultáneamente. También la simultaneidad de lo no-simultáneo (Gleichzeitigkeit des Ungleichzeitigen) -uno de los fenómenos históricos más esclarecedores- posee un rasgo en común con esos "estratos de tiempo": aquello que no se produce completamente en un mismo tiempo; fenómenos que en términos diacrónicos o sincrónicos suponen contextos vitales heterogéneos. Desde la perspectiva de la teoría del tiempo, todos los conflictos, compromisos y consensos provienen de tensiones y líneas de ruptura -otra vez la metáfora espacial-; experiencias contenidas en distintos estratos de tiempo que ellos pueden suscitar.
\end{abstract}

\footnotetext{
${ }^{1}$ Reinhart Koselleck, "Einleintung“, Zeitschichten. Studien zur Historik, Frankfurt am Main, Suhrkamp Verlag, 2000, pp. 9-16. Traducción de Martín Baigorria, financiada por el PICT “Actualidad del pasado. Búsquedas y obstáculos a través de las perspectivas de Walter Benjamin y Reinhart Koselleck", FONCyT.
} 
Así queda planteado, a grosso modo, el marco dentro del cual se mueven estos ensayos. Dejo a un lado los trabajos referidos específicamente a la historia conceptual, la historiografía o la historia social, que publicaré en una edición aparte, para concentrarme en los escritos donde se develan aquellas líneas de fuga primordialmente asociadas a la teoría del tiempo.

Una de mis tesis preliminares es que los tiempos históricos se distinguen fundamentalmente del tiempo condicionado por la naturaleza, incluso aunque ambos se influyan entre sí. Las órbitas circulares del sol, los planetas, la luna, las estrellas o la rotación de la Tierra suponen medidas de tiempo constantes: años, meses, días y "constelaciones", así como el orden sucesivo de las estaciones del año. Todas estas trayectorias de cursos del tiempo surgen dadas al hombre, incluso aunque desde el comienzo haya aprendido a interpretarlas y a calcularlas gracias a sus logros culturales e intelectuales. Nuestros diversos calendarios y cronologías, nuestros datos y estadísticas se apoyan en tales medidas de tiempo, tomadas de la naturaleza, aunque descubiertas por los hombres, pero que se sustraen a su libre arbitrio. Los modos de referirnos a los tiempos naturales preexistentes [vorgegebene Naturzeiten] conservan así un sentido indisputable.

La metáfora específica de los "estratos de tiempo" apareció recién a partir del siglo XVIII, luego de que la antigua historia natural (historia naturalis) hubiera sido temporalizada. Kant y Buffon abrieron el nuevo horizonte temporal incluyendo dentro de su perspectiva histórica toda la Tierra y sus individuos, pertenezcan estos al ámbito de la biología, la zoología o la antropología. Kant se encontraba en la búsqueda de un nuevo concepto que pudiera separar aquello que él llamaba la "historia de la naturaleza" ("Naturgeschichte") de la historia humana. Pero ni los conceptos de "fisiogonía" ("Physiogonie") o "arqueología de la naturaleza" prevalecieron en los usos lingüísticos de la ciencia. Se prefirió conservar el término "historia natural" ("Naturgeschichte"), temporalizado a partir de entonces. ${ }^{2}$

Kant temporaliza (verzeitlichte) el acto singular de la creación, que hasta ese momento pertenecía al ámbito de la teología. "La creación no es la obra de un acontecimiento único" -ella comprende y estructura el proceso de la naturaleza, infinitamente abierto hacia el futuro-. "La creación nunca está terminada [...] La obra que lleva adelante posee una relación con el tiempo dentro del cual se despliega." Kant se sirve de imágenes físicas que usa como metáforas al referirse al progresivo proceso de formación de la naturaleza: "Para alcanzar la perfección pasarán millones de años y montañas enteras de millones de siglos, durante los cuales se formarán siempre nuevos mundos y órdenes mundiales, uno detrás del otro, desde el centro de la naturaleza hasta sus extensiones más lejanas". ${ }^{3}$ Vemos entonces cómo la imagen de los estratos de tierra convertidos en montañas libera un recorrido temporal (Zeitverläufe) consistente en millones de siglos; una metáfora inimaginable hasta entonces.

Carus completa esa recomposición semántica alejándose de la historia de la Tierra como acontecimiento único, al hacer "concordar ciertas formaciones montañosas con la estructura de su masa" y descubrir entonces que dicha "estructura interna resulta de la historia de estas montañas". El origen geológico del concepto de estructura histórica se hace evidente para el

\footnotetext{
${ }^{2}$ Véase Reinhart Koselleck, "Geschichte, Historie", en Geschichtliche Grundbegriffe, editado por Otto Brunner et al., Stuttgart, 1975, vol. 3, pp. 678-682: "Von der historia naturalis zur "Naturgeschichte"”.

${ }^{3}$ Kant, Allgemeine Naturgeschichte und Theorie des Himmels, Werke, Wilhelm Weischedel, vol. 1, Vorkritische Schriften, p. 335.

${ }^{4}$ Carl Gustav Carus, Neun Briefe über Landschaftsmalerei, 8, en Romantische Kunstlehre, Friedmar Apel (ed.), Frankfurt am Mein, 1992, p. 265 (Bibliothek der Kunstliteratur).
} 
uso lingüístico actual. Por eso apenas puede resultar extraño que, en una reformulación semántica más amplia, la historia humana sea interpretada mediante metáforas que expresan nuevos y largos períodos de tiempo. Cuando Görres intentó explicar el "carácter de la época moderna", su propio tiempo -ya en aquella época también el "nuestro"- recurrió al símil geológico: "El tiempo antiguo vale para la época moderna [neue Zeit] lo mismo que, en la historia de la Tierra, los macizos originales valen para los estratos montañosos [Flözgebirge]". ${ }^{5}$ Montañas compactas y homogéneas conquistaron la tierra y cargaron con sus formaciones subsiguientes; la época moderna se asemejaría así a las más recientes e inquietas capas del tiempo. Sin menoscabar la especulación romántica en la que incurre Görres, algo se vuelve claro: aquello que antes había integrado los mitos de la creación y las cosmogonías obtiene la forma de estructuras históricas [geschichtliche Strukturen]. Los largos períodos de tiempo de la historia de la Tierra, incluidos allí sus sedimentos y erupciones, se conectan entre sí para constituir una "prehistoria" de la humanidad ["Vorgeschichte"] cuyos rasgos estructurales análogos no son meramente metafóricos.

Existen de hecho factores metahistóricos cuyo control escapa del dominio humano. A esa categoría pertenecen todas las condiciones geográficas y climáticas, además de la geología, sobre las cuales los hombres pueden influir sin dominarlas completamente. Eso nos conduce a aquellos presupuestos naturales que posibilitan nuestra experiencia antropológica del tiempo. En términos puramente zoológicos compartimos con los animales tales precondiciones: el reloj biológico, al cual nuestro cuerpo se halla constreñido; y el instinto sexual esencial para la reproducción de cada generación situada entre el nacimiento y la muerte, que -como indica Heidegger- moldean nuestra existencia temporal. Pero eso que tenemos en común con los animales queda moldeado en términos culturales: la muerte a través de la muerte motivada por causas políticas; el sexo intensificado por medio del deseo y el terror [Lustund Terror]; la necesidad de comer y beber, exacerbada por la ascesis o las espirales del goce.

Una signatura común de estas formas antropológicas de comportamiento, también natural, es que remiten siempre a la recurrencia. A pesar de su enorme variabilidad cultural, esos impulsos o necesidades se nutren de su repetibilidad, sin la cual no podrían surgir ni ser satisfechos. El modelo temporal de la repetición es un testimonio de la constancia de la historia humana, que en nuestra -así llamada- prehistoria [Vorgeschichte] se remonta a unos dos millones de años.

Eso que Ferdinand Braudel denominó la "larga duración” (longue durée), aquella duración extensa estructuralmente subyacente o previa a toda historia individual, debe ser diferenciada en el plano temporal. O bien se trata de condiciones previas de tipo geográfico o biológico, cuya duración se sustrae de la aprehensión humana; o bien consiste en una estructura de repetición (Wiederholungs Struktur) adoptada conscientemente por el hombre, ritualizada y enriquecida a través de la cultura: se identifica con aquella continuidad que ayuda a estabilizar nuestras respectivas sociedades. El Mar Mediterráneo investigado por Braudel, cuyo marco extrahumano condiciona historias seculares, posee otro tipo de duración, distinta de la continuidad surgida de la acción humana. Habría así dos estratos del tiempo distintos que parecen remitir a duraciones similares. Pero una de ellas, la duración constante garantizada por el orden

\footnotetext{
${ }^{5}$ Joseph Görres, Korruskationen [=Wetterleuchten], en Ausgewählte Werke, Wolfgang Frühwald, Freiburg, Basel-
} Wien, 1978, vol. 1, p. 971. 
natural, puede ser efectiva de manera inconsciente adquiriendo solo a posteriori una conciencia mayor. Las precondiciones geográficas o biológicas de la historia humana no pueden controlarse completamente, incluso a pesar de los progresos efectuados por las ciencias naturales. El otro tipo de duración vive de una repetición deseada y deliberada. Garantiza persistencia y continuidad en los comportamientos sociales. En términos empíricos las estructuras de repetición naturales y humanas se interrelacionan, pero desde la perspectiva de la teoría del tiempo deben ser diferenciadas.

Por eso, insistamos en lo siguiente: nuestras estructuras de repetición no pueden ser reducidas a aquellos ciclos propios de las órbitas cósmicas. Desde la antigüedad esa metáfora circular juega un rol destacado en innumerables interpretaciones históricas. Sin embargo, carece de una peculiaridad temporal que no es tanto un "eterno" retorno, sino más bien una repetición ejecutada en la actualidad: toda acción y toda constelación histórica singular, formada por hombres también únicos y singulares, contienen estratos de tiempo que se repiten constantemente. Ellos permiten, condicionan y limitan las posibilidades de la acción a la vez que la liberan. Para los participantes de una boda esta puede ser un hecho individual y singular -sobre todo para la pareja-; pero los rituales con los cuales estos eventos son preparados -o sea, costumbres, usos y leyes- aseguran un tipo particular de estabilidad. Su capacidad de repetición es condición indispensable para todos los casos individuales.

En los estudios siguientes abordaremos lo que se denomina el largo, el medio y el corto plazo para reflexionar sobre aquello que se repite en su seno, permitiendo las acciones singulares (einmaliges Tun und Handeln). El enfoque metodológico de Fernand Braudel será desconectado de la duración larga, corta o situacional para ser reconducido a un modelo antropológico común, que contiene en su seno distintos estratos de tiempo. Sin este tipo de diferenciación, ninguna historia puede ser discernida o representada. Los rituales y los dogmas se asientan en su repetibilidad para garantizar su perdurabilidad. Las costumbres, las reglas jurídicas y las leyes se sostienen sobre ese uso repetido, sin el cual el orden y la justicia-siempre tan en peligro- no serían posibles. Toda constitución, institución y organización política, social o económica se nutre de un mínimo de repetición, sin el cual no serían susceptibles de adaptación o renovación. También las artes, tan pretendidamente originales, viven de la inclusión de posibilidades preexistentes. Toda recepción contiene o delata repeticiones.

Algo análogo vale para la historia del lenguaje. La pragmática de la lengua siempre es situacional y única, vinculada a los acontecimientos o a una acción lingüística creadora de un evento. La semántica resiste por el contrario más tiempo, es menos variable, muta lentamente. Pues en toda semántica hay contenidas potenciales interpretaciones que ejercen su influjo a lo largo de generaciones. Sin su conocimiento previo no habría posibilidad de entendimiento, ya sea simultáneo o de una época a otra. Por último, la estructuras gramatical y sintáctica se modifica de modo aun más lento, apenas puede ser influida directamente.

Todos los ámbitos de la vida y la acción humana contienen así distintas estructuras de repetición que varían gradualmente con distinta velocidad. De ninguna manera puede suponerse que esos cambios surjan de modo paralelo o en simultáneo; más allá de que estos coincidan dentro de una cronología y de que encuentren relaciones entre sí, por cierto difíciles de dilucidar.

El modo y el contexto en que el registro lingüístico del mundo varía respecto de la -así llamada- historia real, a la vez, la condiciona y libera. Como puede verse en el curso de estas reflexiones, los argumentos de mi maestro Hans-Georg Gadamer dan cuenta de una perspec- 
tiva teórica diferente. Me hallo igualmente inclinado a interpretar la relación entre la historia del lenguaje y la historia de las cosas de manera aporética: en el lenguaje hay más o menos tanto contenido y datos expresables como los hay en la historia real (wirklichen Geschichte). Y a la inversa: toda historia posee, más o menos, tanto contenido como aquello que fue dicho sobre ella. Precisamente por ese motivo los relatos históricos deben siempre reescribirse una y otra vez, reformulando la historia anterior.

Sin pluridimensionalidad de los tiempos históricos sería imposible aventurar pronósticos. Es cierto que eventos y personas, acciones y omisiones, debido a su singularidad, son apenas predecibles. Pero tal vez sí puedan analizarse condiciones espaciales más o menos repetidas dentro de las cuales podrían tener lugar otros acontecimientos futuros. Esta capacidad de prognosis se nutre de un mínimo de reiterabilidad que inevitablemente debe ser presupuesto; de lo contrario la humanidad se lanzaría todos los días a una nada infinita.

Sin embargo, los límites de esos cálculos no tardan en hacerse evidentes cuando las coordenadas de la utopía se temporalizan y son lanzadas al futuro: en un abrir y cerrar de ojos producen lo contrario que deseaban alcanzar.

Dado que las estructuras de repetición nunca se reproducen de la misma manera, se plantea como una necesidad la pregunta en torno a las formas que caben a la velocidad de esos cambios, o sea, la pregunta por su demora o aceleración. Esta cuestión solo puede abordarse si las expectativas subjetivas y sus objetivos, logrados o no, se distinguen de aquellos factores que en el contexto de la sociedad técnico-industrial imponen a los seres humanos una aceleración científicamente calculable.

Expectativas de aceleración en el sentido de un anhelado acortamiento del tiempo han existido desde la época del apocalipsis judeo-cristiano. Pero de una aceleración capaz de modificar la realidad solo puede hablarse recién en nuestro mundo moderno, marcados por la experiencia de la técnica. En la percepción de los participantes y los afectados ambos van de la mano, sin poder ser remitidos uno a otro de manera causal. "Este desarrollo presuroso ("Eilentwicklung") [...] desea lo efímero, por la mitad de la paga anhela la experiencia de un hombre de medio siglo." Así reformula Jean Paul la expectativa del apocalipsis cristiano en los términos de la experiencia de la aceleración moderna. ${ }^{6}$ Pero ese "desarrollo acelerado", expresado por agudeza por Jean Paul, no es aún idéntico a la aceleración constatable en la historia real. Para poder hablar sobre ella de manera fundamentada, también aquí debe ser separada la forma lingüística de la circunstancia en sí misma.

En los últimos estudios de este volumen vamos a mostrar hasta qué punto las perspectivas historiográficas se remiten a las premisas de la teoría del tiempo (zeittheoretischen Prämissen), a partir de las cuales debe ser comprendida la historia real. Siempre se necesitan categorías formalizadoras que permitan reconstruir historias concretas haciéndolas ante todo comparables. Las determinaciones temporales sin elementos intuitivos requieren a su vez de contenidos. Las categorías formales: adentro/afuera, arriba/abajo, antes/después pertenecen a figuras fundamentales, rastreables en todas las historias, incluso aunque sus contenidos sean muy distintos. Son determinaciones de diferencias antropológicas, de las cuales surgen sus consecuencias temporales. Vamos a comparar así cinco tipos de transcursos temporales que buscan conectar, cada uno a su manera, distintas formas de justicia con su experiencia histórica.

\footnotetext{
${ }^{6}$ Jean Paul, Werke, N. Miller (ed.), Munich, 1980, vol. 5, p. 929.
} 
Un caso muy especial se da cuando algo ha acontecido no solamente antes que, al mismo tiempo, o después de, sino demasiado temprano o demasiado tarde. Tal determinación se dirige a un contexto de acción único y singular, provisto de un kairos, al cual pueden honrar, fallar, o pasar de largo. Por eso la categoría del atraso, que hoy en día tan complacientemente se aplica a la historia alemana, solo se refiere a un punto del tiempo relevante para esa acción en concreto. Esta categoría del atraso no es sin embargo apropiada cuando se aplica a formaciones sociales como Estados o sociedades, tampoco a culturas o lenguajes. Un atraso apunta a una oportunidad desaprovechada, un deseo retrógrado que de manera ideológica prescribe una recuperación expeditiva del pasado. Pertenece al lenguaje programático de la política y prescinde de todo rigor analítico; ya que podemos suponer con Herder que cada historia entraña su propia medida temporal. Los juicios morales son necesarios pero no constitutivos de aquello que ya ha acontecido. 